\title{
The Genetic and Environmental Association Between Parental Monitoring and Risk of Cannabis, Stimulants, and Cocaine Initiation in a Sample of Male Twins: Does Parenting Matter?
}

\author{
Emily L. Olivares, ${ }^{1}$ Kenneth S. Kendler, ${ }^{1,2}$ Michael C. Neale ${ }^{1,2}$ and Nathan A. Gillespie ${ }^{1,3}$ \\ ${ }^{1}$ Virginia Institute for Psychiatric and Behavior Genetics, Virginia Commonwealth University, Richmond, Virginia, USA \\ ${ }^{2}$ Human and Molecular Genetics, Virginia Commonwealth University, Richmond, Virginia, USA \\ ${ }^{3}$ OIMR Berghofer Institute of Medical Research, Brisbane, Queensland, Australia
}

\begin{abstract}
Our aim was to test the direction of causation between self-report parental monitoring (PM) and the liability to illicit drug initiation (DI) as indicated by cannabis, cocaine, and stimulants. We fitted a multiple indicator model to test causal and non-causal models based on a large, genetically informative cross-sectional sample of male twins. The sample comprised 1,778 males aged 24-62 years from the Virginia Adult Twin Study of Psychiatric and Substance Use Disorders. Data came from self-report measures of lifetime cannabis, stimulants, and cocaine initiation, and retrospective assessment of PM between ages 8-17 years. Multivariate modeling showed that familial aggregation in PM and DI were both explained by a combination of additive genetic and shared environmental effects. Moreover, the significant association between PM and DI was best explained by a correlated liability model versus causal models. PM has typically been assumed to be an environmental, causal risk factor for drug use and has been shown to be among the more salient environmental risk factors for illicit DI. Our data were not consistent with this causal hypothesis. Instead, a correlated liability model in which PM and risk of DI share common genetic and environmental risks provided a better fit to the data.
\end{abstract}

- Keywords: parental monitoring, parenting, cannabis, stimulants, cocaine, causality

Drug use disorders (DUDs) are complex traits influenced by a variety of environmental factors and genetic risks. Depending on the substance, genetic risks account for 40$70 \%$ of the liability to drug initiation (DI) and DUDs (Kendler \& Prescott, 2006) with increasing heritability as individuals progress to DUDs (Kendler et al., 2012). The remaining variance can be predicted by a variety of socialenvironmental risks often identifiable in early to midchildhood (Caspi et al., 1996; Casswell et al., 2002; Chassin et al., 2002; Colder et al., 2002; Dubow et al., 2008; Ellickson et al., 2004; Englund et al., 2008; Jackson \& Sher, 2006; Li et al., 2001; Maggs et al., 2008; Manzardo et al., 2005; Pitkanen et al., 2008; Wiesner et al., 2007; Windle et al., 2005), which includes personality (McGue et al., 1999), externalizing behaviors (Boyle et al., 1992; Fergusson \& Lynskey, 1998; Helzer et al., 1992; Lynskey \& Fergusson, 1995; Szobot \& Bukstein, 2008; Young et al., 1995), and environmental factors such as parental monitoring (PM) (Dishion \& Loeber, 1985; Gillespie, Lubke et al., 2012), childhood sexual or physical abuse (Glaser et al., 1977; Kendler, Bulik et al., 2000), parental attitudes toward drug use (Gillespie, Lubke et al., 2012; McDermott, 1984), household drug use (Gfroerer, 1987), deviant peer group affiliation (Jones et al., 1976), drug availability (Freisthler, Gruenewald, Johnson et al., 2005; Freisthler, Needell, \& Gruenewald et al., 2005; Gillespie et al., 2009), and participation in prosocial activities (Kendler \& Myers, 2009). Among these risks, PM has been shown to be one of the most salient (Gillespie, Lubke et al., 2012; Latendresse et al., 2008; 2009).

PM is typically measured in terms of parental knowledge of children's whereabouts and degree of parental supervision. Although PM is a significant predictor of both

RECEIVED 15 January 2016; ACCEPTEd 4 May 2016

ADDRESS FOR CORRESPONDENCE: Nathan A. Gillespie, Virginia Institute for Psychiatric and Behavior Genetics, Department of Psychiatry Virginia Commonwealth University, 800 East Leigh Street, Biotech 1, Suite 101, Richmond VA 23219-1534, USA. E-mail: nathan.gillespie@vcuhealth.org 
cannabis initiation and average cannabis consumption over time (Gillespie, Lubke et al., 2012), the genetic and environmental association between PM and the risk of DI remains unclear. In addition to the association being driven by correlated genetic and environmental risks, DI may be phenotypically contingent upon (reduced) PM or vice versa. In lieu of genetically informative longitudinal data, alternative and innovative statistical methods can be applied to provide some capacity to infer causation. These include propensity analyses (Kendler \& Gardner, 2010), cross-panel designs, or modeling direction of causation based on pairs of genetically informative relatives measured on a single occasion (Heath et al., 1993).

Direction of causation modeling based on crosssectional and genetically informative data has been applied to a number of complex behavioral phenotypes (Duffy \& Martin, 1994; Gillespie, Gehrman et al., 2012; Gillespie et al., 2012; Neale, Walters et al., 1994). Provided several assumptions are satisfied, differences in the patterns of crosstwin, cross-trait correlation can allow researchers to falsify a hypothesis about the direction of causation between two variables measured on a single occasion (Heath et al., 1993). Therefore, using a genetically informative sample of male twins, our aim was to determine the direction of causation between PM and illicit DI. We fitted a model that predicted that the association between PM and the liability to DI was explained by shared genetic and environmental risk factors, which we then compared to models that predicted a reciprocal causation between PM and DI, and unidirectional causation (PM-to-DI and DI-to-PM).

\section{Material and Methods}

\section{Subjects}

Described in detail elsewhere (Kendler \& Prescott, 2006), this report is based on data collected from a second and third wave of interviews between 1994 and 2004 as part of an ongoing study of adult male twins from the Virginia Adult Twin Study of Psychiatric and Substance Use Disorders (VATSPUD). Briefly, twins were eligible for participation in this study if one or both twins were successfully matched to birth records, were a member of a multiple birth with at least one male, were Caucasian, and were born between 1940 and 1974. Of 9,417 eligible individuals for the first wave (1993-1996), 6,814 (72.4\%) completed the initial interviews. At least 1 year later, we contacted those who had completed the initial interview to schedule the second interview. The second interview was completed by $83 \%$ of those eligible or 4,203 males comprising 1,189 complete twin pairs and 1,825 singletons. Twin pairs (no singletons) who completed the second interview were eligible to participate in a third interview (2000-2004). The VATSPUD was designed to study the nature and pattern of risk and protective factors for drug use and DUDs across adolescence and young adulthood. This third interview was completed by $75 \%$ of those eligible or 1,778 males, aged $24-62$ years ( $\mu=40.3, S D=9.0$ ) from 745 complete twin pairs and 288 singletons.

In both interviews, most subjects $(\sim 90 \%)$ were interviewed by telephone. A small number were interviewed in person because of subject preference, residence in an institutional setting (usually jail), or not having a telephone. Subjects were informed about the goals of the study and provided informed consent before interviews. Interviewers had a master's degree in a mental health-related field or a bachelor's degree in this area plus 2 years of clinical experience. The two members of a twin pair were each interviewed by different interviewers. The VATSPUD was approved by the Virginia Commonwealth University institutional review board.

\section{Zygosity and Interview Protocol}

Zygosity was diagnosed using a combination of self-report measures, photographs, and DNA analysis.

\section{Measures of Drug Initiation and Parental Monitoring}

The second interview assessed lifetime drug use for six substances: cannabis (marijuana and hashish); sedatives (quaalude, Seconal, and Valium); stimulants (speed, ecstasy, and Ritalin); cocaine (intranasal, freebase, and crack); opiates (heroin, Demerol [meperidine hydrochloride], and morphine); and hallucinogens (lysergic acid diethylamide, mescaline, and phencyclidine). For substances that could be obtained legally, non-medical use was defined as use: (1) without a doctor's prescription; (2) in greater amounts or more often than prescribed; or (3) for any other reason than a doctor said it should be taken. Subjects who endorsed having 'ever tried [drug]' were then asked two questions: 'How old were you the first time you took [drug]?' and 'How old were you when you used [drug] the most?'. A DI score (Yes/No) was then calculated for each substance and scored positive if DI was confirmed by responses to both these items. Because of the need to maintain computational efficiency, we analyzed cannabis, stimulants, and cocaine as these were the three most commonly initiated illicit substances.

Because the data collected at Wave 3 interview were retrospective, they are potentially contaminated by recall bias and telescoping effects (Pickles et al., 1994). Therefore, our study used a Life History Calendar format (Freedman et al., 1988) to improve the data quality. This method has been shown empirically to improve the accuracy of retrospective reporting by providing multiple cues to improve the chance of accurate recall (Belli, 1998; Freedman et al., 1988). This makes the task more akin to the accurate and well-retained process of recognition than to the less reliable task of free recall.

The third interview included a retrospective assessment of PM between ages 8-17 years using 11 items selected on the basis of previous work examining parental effects 
on risk of drug use and delinquency (Celdran et al., 1976; Ingram, 1976; Stattin \& Kerr, 2000). These items asked subjects questions such as how much their parents or guardians knew who their friends were, how they spent their money, and what they did with their free time, and where they were at night and so forth. Response options were [their parents] 'didn't know', 'knew a little', or 'knew a lot'. PM latent factor scores were estimated for each individual in the Classic Mx software program (Neale, 1999). Again, in order to maintain computational efficiency, we restricted our analyses to the three most prevalent PM items: 'How much did your parents know about your friends?'; 'How much did your parents know about how you spent your money?'; and 'How much did your parents know about how you spent your free time?'

There were 2,576 subjects with complete DI, and 1,758 subjects with complete PM data. Depending on the substance, this included 1,749 to 1,754 subjects with both DI and PM data. For each of the three drug classes, there were 694 monozygotic (MZ) and 484 dizygotic (DZ) twin pairs, as well as 220 singletons with complete DI data. For PM, there were $454 \mathrm{MZ}$ and $280 \mathrm{DZ}$ twin pairs, respectively with complete data, plus 290 singletons.

\section{Raw Ordinal Data Analysis}

All data were analyzed using raw data methods in the OpenMx software implemented in R (Boker et al., 2015). This approach assumes that the observed ordinal categories within each item are an imprecise measure of a latent normal distribution of liability, and that the liability distribution for each variable has one or more thresholds that discriminate between the categories. Thresholds can be conceived of as cut points along a normal distribution that classifies individuals in terms of a probability or risk of endorsing one of two or more discrete (ordinal) categories. The DI and PM thresholds were adjusted for the linear effects of age, and before fitting univariate and multivariate models, were used likelihood ratio chi-square tests to confirm the equality of thresholds within twin pairs and across zygosity. These preliminary tests of threshold homogeneity are analogous to tests of mean and variance homogeneity in the case of continuous data.

\section{Univariate and Multivariate Genetic Analyses}

Based on standard biometrical genetic model-fitting methods (Neale \& Cardon, 1992) that exploit the expected genetic and environmental correlations for $\mathrm{MZ}$ and $\mathrm{DZ}$ twin pairs, our models assumed that the total variance in each of the observed items and latent constructs can be decomposed into additive (A) genetic, shared environment (C), and non-shared or unique (E) environmental variance components. Because $\mathrm{MZ}$ twin pairs are genetically identical, correlations for the A effects are 1.0. For DZ twin pairs who on average share half of their genes, the correlations for the A effects are 0.5. An important assumption of biomet-

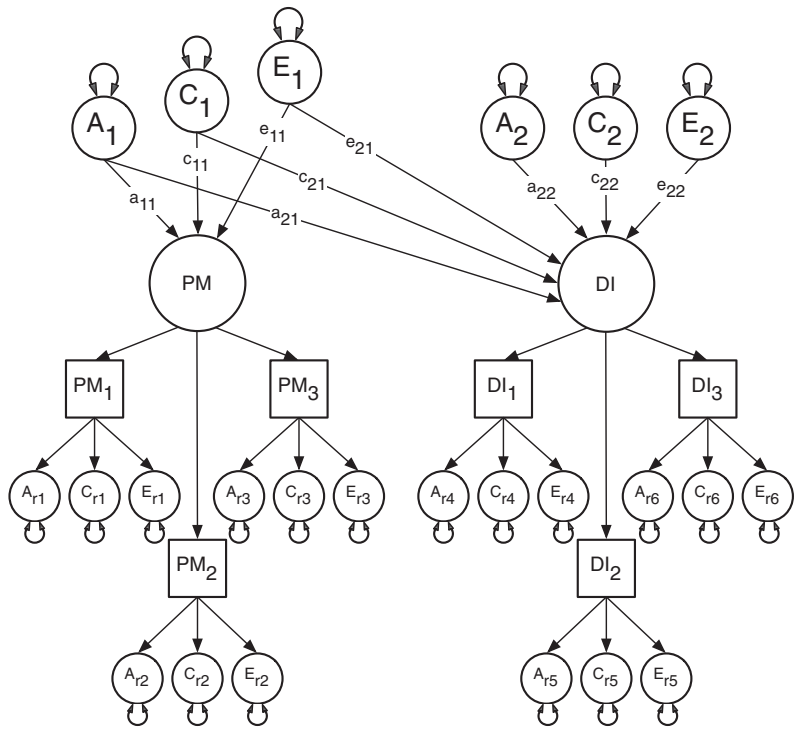

(a)

\section{FIGURE 1a}

Cholesky decomposition illustrating the association between Parental Monitoring (PM) and Drug Initiation (DI) in which the sources of covariance between PM and DI are decomposed into shared genetic $\left(a_{2,1}\right)$ and environmental $\left(c_{2,1}\right.$ and $\left.e_{2,1}\right)$ effects. This model also models the genetic $\left(a_{2,2}\right)$ and environmental $\left(c_{2,2}\right.$ and $\left.e_{2,2}\right)$ effects unique to $D I\left(a_{2,2}, c_{2,2}, e_{2,2}\right)$.

Note: $A_{1}, C_{1}$ and $E_{1}=$ latent additive genetic, shared, and nonshared environmental risks for $P M, A_{2}, C_{2}$ and $E_{2}=$ latent additive genetic, shared, and non-shared environmental risks for $\mathrm{DI}$, $\mathrm{PM}$ and $\mathrm{DI}=$ common factors as indicated by observed phenotypic symptoms $\mathrm{PM}_{1-3}$ and $\mathrm{DI}_{1-3}$ respectively, each with their own item specific latent genetic and environmental risk factors, $\mathrm{PM}_{1}$ $=$ parent's knowledge of child's friends, $\mathrm{PM}_{2}=$ parent's knowledge of how child spent their money, $\mathrm{PM}_{3}=$ parent's knowledge of how child spent their free time, $\mathrm{DI}_{1}=$ cannabis initiation, $\mathrm{DI}_{2}=$ stimulant initiation, $\mathrm{DI}_{3}=$ cocaine initiation.

rical genetic model is that shared environmental effects $(C)$ are perfectly correlated among $\mathrm{MZ}$ and $\mathrm{DZ}$ twin pairs alike. Non-shared environmental effects are by definition uncorrelated and also reflect measurement error, including shortterm fluctuations.

We used this method first to estimate the contribution of genetic and environmental risks (A, C, and E) in the univariate analyses of the PM and DI items. In the multivariate analyses, we then modeled the direction of causation between the latent factors for PM and DI because measurement error reduces the statistical power for resolving alternative causal hypotheses (Neale, Duffy et al., 1994; Neale, Walters et al., 1994). This approach assumes that measurement error occurs at the level of the items or indicator variables and so is uncorrelated across factors (Heath et al., 1993). Specifically, we compared the fit of a correlated liability model against four causal models using maximum likelihood estimation in the R-based OpenMx software package (Boker et al., 2015). The models were: (1) a comparison or correlated liability model illustrated in Figure 1a; (2) a 
TABLE 1

Measures of Association (Polychoric Correlations) Between Parental Monitoring and Drug Initiation Items Along With Twin Pair (Polychoric) Correlations and 95\% Confidence Intervals for Each Item

\begin{tabular}{|c|c|c|c|c|c|c|c|c|}
\hline \multirow[b]{2}{*}{ Items } & \multicolumn{6}{|c|}{ Polychoric correlations } & \multicolumn{2}{|c|}{ Twin pair correlations } \\
\hline & 1. & 2. & 3. & 4. & 5. & 6. & $\mathrm{MZ}$ & DZ \\
\hline 1. Parents' knowledge of child's friends & 1.00 & & & & & & $0.47(0.37-0.56)$ & $0.39(0.25-0.51)$ \\
\hline 2. Parents' knowledge of how child spent their money & 0.74 & 1.00 & & & & & $0.45(0.36-0.54)$ & $0.30(0.15-0.43)$ \\
\hline 3. Parents' knowledge of how child spent their free time & 0.72 & 0.82 & 1.00 & & & & $0.47(0.36-0.56)$ & $0.38(0.24-0.51)$ \\
\hline 4. Cannabis initiation & -0.24 & -0.31 & -0.34 & 1.00 & & & $0.81(0.76-0.85)$ & $0.55(0.45-0.64)$ \\
\hline 5. Stimulants initiation & 0.27 & -0.32 & -0.31 & 0.76 & 1.00 & & $0.66(0.53-0.76)$ & $0.29(0.10-0.47)$ \\
\hline 6. Cocaine initiation & -0.22 & -0.25 & -0.25 & 0.85 & 0.78 & 1.00 & $0.78(0.68-0.85)$ & $0.45(0.25-0.61)$ \\
\hline
\end{tabular}

Note: All correlations adjusted for the effects of age at interview, sex, and cohort on item thresholds.

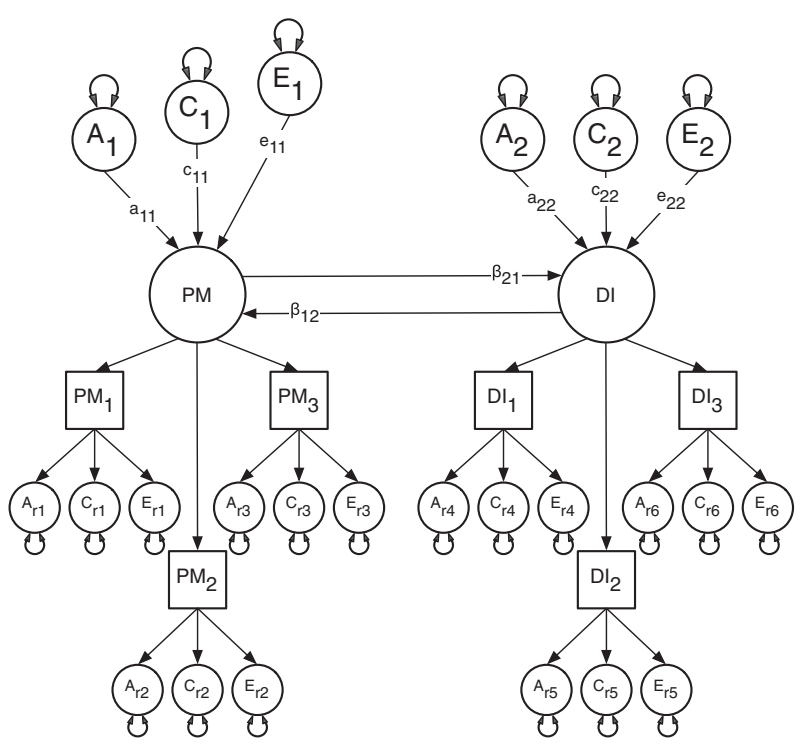

(b)

\section{FIGURE 1b}

Illustrative model of the direction of causation between the latent factors for Parental Monitoring (PM) and Drug Initiation (DI). This model approach predicts the relationship between PM and DI is explained by a reciprocal interaction, or causal parameters $\left(\beta_{21}\right.$ and $\left.\beta_{12}\right)$, at the latent factor level.

Note: $A_{1}, C_{1}$ and $E_{1}=$ latent additive genetic, shared, and nonshared environmental risks for $P M, A_{2}, C_{2}$ and $E_{2}=$ latent additive genetic, shared, and non-shared environmental risks for DI, $\mathrm{PM}$ and $\mathrm{DI}=$ common factors as indicated by observed phenotypic symptoms $\mathrm{PM}_{1-3}$ and $\mathrm{Dl}_{1-3}$ respectively, each with their own item specific latent genetic and environmental risk factors, $\beta_{21}=$ causal pathway from PM to DI, $\beta_{12}=$ causal pathway from DI to $\mathrm{PM}, \mathrm{PM}_{1}=$ parent's knowledge of child's friends, $\mathrm{PM}_{2}=$ parent's knowledge of how child spent their money, $\mathrm{PM}_{3}=$ parent's knowledge of how child spent their free time, $\mathrm{DI}_{1}=$ cannabis initiation, $\mathrm{DI}_{2}=$ stimulant initiation, $\mathrm{DI}_{3}=$ cocaine initiation.

reciprocal causation model illustrated in Figure 1b; (3-4) two unidirectional causation models. The correlated liability model is identical to bivariate Cholesky decomposition (Neale \& Cardon, 1992) and is the null hypothesis because it predicts no causal association between the latent PM and DI factors. Instead, any phenotypic association is attributable to common or correlated genetic and environmental latent effects, that is, via the $a_{11}$ and $a_{21}, c_{11}$ and $c_{21}$, and $e_{11}$ and $\mathrm{e}_{21}$ pathways. Under the reciprocal causation and unidirectional models, any association between PM and DI arises because of direct phenotypic causality between the latent PM and DI factors via the $\beta_{12}$ and $\beta_{21}$ pathways.

\section{Model Comparisons}

The correlated liability model was compared to the reciprocal and unidirectional causal models using likelihood-ratio chi-squared tests with degrees in freedom being equal to the degrees of freedom between the models. The best-fitting model was chosen on the basis of parsimony, that is, the model with non-significant changes in the chi-square and the smallest number of parameters. To this end, the Akaike Information Criterion (AIC) was calculated for each model and the model with the lowest index value was chosen as the best fitting.

\section{Results}

Tests of Threshold Homogeneity and Polychoric Correlations

We found no significant differences in the threshold distribution for the three PM and three DI items within twin pairs or across zygosity. As shown in Table 1, the polychoric correlations between the DI and PM items were all moderate, ranging from -0.22 to -0.34 , such that lower levels of PM were associated with increased risk of DI. The patterns of $\mathrm{MZ}$ and $\mathrm{DZ}$ twin pair correlations suggest a pattern of familial aggregation for cannabis initiation attributable to a combination of additive genetic and shared environmental risk factors. For stimulants and cocaine, the twin pair correlations suggest that familial aggregation is more likely explained by additive genetic risks alone. For the three PM items, all DZ twin pair correlations were greater than half the $M Z$ twin pair, suggesting a combination of genetic and shared environmental risk factors.

\section{Univariate Analyses}

Standardized univariate components of variance for PM and DI items are shown in Table 2. Additive genetic risks explained between $17 \%$ and $31 \%$ of the variance in PM. Although shared environmental risk factors explained $14 \%$ to $30 \%$ of the variance in the PM items, the $95 \%$ confidence 


\section{TABLE 2}

Variance Components (Standardized) in the Parental Monitoring and Drug Initiation Items Attributed to Additive Genetic (A), Shared Environment (C), and Non-Shared Environmental (E) Effects Along With Their $95 \%$ Confidence Intervals

\begin{tabular}{llll}
\hline Items & $A$ & $C$ & $E$ \\
\hline 1. Parents' knowledge of child's friends & $0.17(0.00-0.51)$ & $0.30(0.00-0.50)$ & $0.53(0.43-0.63)$ \\
2. Parents' knowledge of how child spent their money & $0.31(0.00-0.54)$ & $0.14(0.00-0.43)$ & $0.55(0.46-0.65)$ \\
3. Parents' knowledge of how child spent their free time & $0.17(0.00-0.49)$ & $0.30(0.00-0.49)$ & $0.53(0.44-0.64)$ \\
4. Cannabis initiation & $0.42(0.25-0.60)$ & $0.33(0.16-0.49)$ & $0.25(0.21-0.30)$ \\
5. Stimulants initiation & $0.57(0.26-0.74)$ & $0.09(0.00-0.36)$ & $0.34(0.26-0.43)$ \\
6. Cocaine initiation & $0.64(0.34-0.79)$ & $0.08(0.00-0.35)$ & $0.28(0.21-0.36)$ \\
\hline
\end{tabular}

\begin{tabular}{|c|c|c|c|c|c|c|}
\hline \multirow{3}{*}{\multicolumn{7}{|c|}{$\begin{array}{l}\text { Multivariate Model Fitting Results for the (1) Non-Causal Correlated } \\
\text { Liability, (2) Reciprocal Causation (PM } \leftrightarrow \text { DI), (3) Uni-Directional Parental } \\
\text { Monitoring Causes Drug Initiation (PM } \rightarrow \text { DI), and (4) Uni-Directional Drug } \\
\text { Initiation Causes Parental Monitoring (DI } \rightarrow \text { PM) Models }\end{array}$}} \\
\hline & & & & & & \\
\hline & & & & & & \\
\hline & $-2 \mathrm{LL}$ & $d f$ & $\Delta-2 \mathrm{LL}$ & $\Delta d f$ & $p$ & $\mathrm{AIC}$ \\
\hline Correlated liability & $14,548.68$ & 12,950 & - & - & - & $-11,351.32$ \\
\hline Reciprocal causation & $14,552.96$ & 12,951 & 4.28 & 1 & .04 & $-11,349.04$ \\
\hline$P M \rightarrow D I$ & $14,596.70$ & 12,952 & 48.03 & 2 & *** & $-11,307.30$ \\
\hline $\mathrm{DI} \rightarrow \mathrm{PM}$ & $14,567.76$ & 12,952 & 19.08 & 2 & *** & $-11,336.24$ \\
\hline
\end{tabular}

Note: All PM and DI thresholds are adjusted for the linear effects of age at interview. $-2 \mathrm{LL}=$ log-likelihood, $\Delta-2 \mathrm{LL}=$ change in log-likelihood which is asymptotically distributed as a chi-square; $\mathrm{AIC}=$ Akaike Information Criteria; ${ }^{* * *} p<.001$.

intervals spanned zero for all three PM items. Additive genetic risks explained between $42 \%$ and $64 \%$ of the variance in the DI items. Shared environmental risk factors explained $33 \%$ of the variance in the cannabis initiation. Confidence intervals for the shared environmental risks for stimulant and cocaine initiation spanned zero.

\section{Multivariate Analysis}

Results for the multivariate modeling fitting are shown in Table 3. The two unidirectional and the reciprocal causation models deteriorated significantly when compared to the (null) correlated liability model. Based on these results and the lowest AIC, the correlated liability was therefore chosen as the best fitting and most parsimonious. Standardized path coefficients for the correlated liability model appear in Figure 2.

\section{Discussion}

PM has been assumed to be an environmental, causal risk factor for DI. Although we found a significant phenotypic association between PM and measures of DI, our data revealed that the liability to DI was not consistent with any causal hypothesis. Instead, a correlated liability model in which PM and risk of DI share common genetic and environmental risks provided a better fit to the cannabis, stimulants, and cocaine data.

Our univariate point estimates for the genetic and environmental risks in drug use were comparable to those reported elsewhere (Gillespie et al., 2013; Kendler et al., 2012;
Verweij et al., 2010). Our analyses also showed that familial aggregation in PM could be explained by a combination of additive genetic effects and environmental risks. This is consistent with previous analyses based on phenotypic correlates of PM such as Parker's Parental Bonding Instrument (PBI; Parker et al., 1979) that have found that, depending on the informant, parenting behaviors are best explained by a combination of genetic and environmental risk factors (Gillespie et al., 2003; Kendler, 1996; Kendler et al., 1997).

Previous reports have shown how family involvement is associated with levels of drug use even after controlling for peer influences (Chassin et al., 1993). In genetically informative studies, PM has been shown to attenuate the impact of genetic risks on other substances such as alcohol (Dick et al., 2009; Dick et al., 2011) and nicotine consumption (Dick et al., 2007). And although the genetic risks for alcohol and nicotine use appear to be maximized under conditions of low social constraint (Dick et al., 2011; Latendresse et al., 2008; 2009), we found no causal impact of the PM on DI or DI on PM. Instead, covariation between self-reports of PM and the liability to DI appears to be attributable to shared, non-causal genetic, and environmental risk factors.

The idea of correlated genetic and environmental risks indexing both PM and DI is consistent with Scarr and McCartney's active model that predicts that individuals seek out environments that they find compatible and stimulating based on motivational, personality, and intellectual aspects of their genotype (Scarr \& McCartney, 1983). Our results are also consistent with genotype-environment correlations (CorGE), which describe situations in which an 


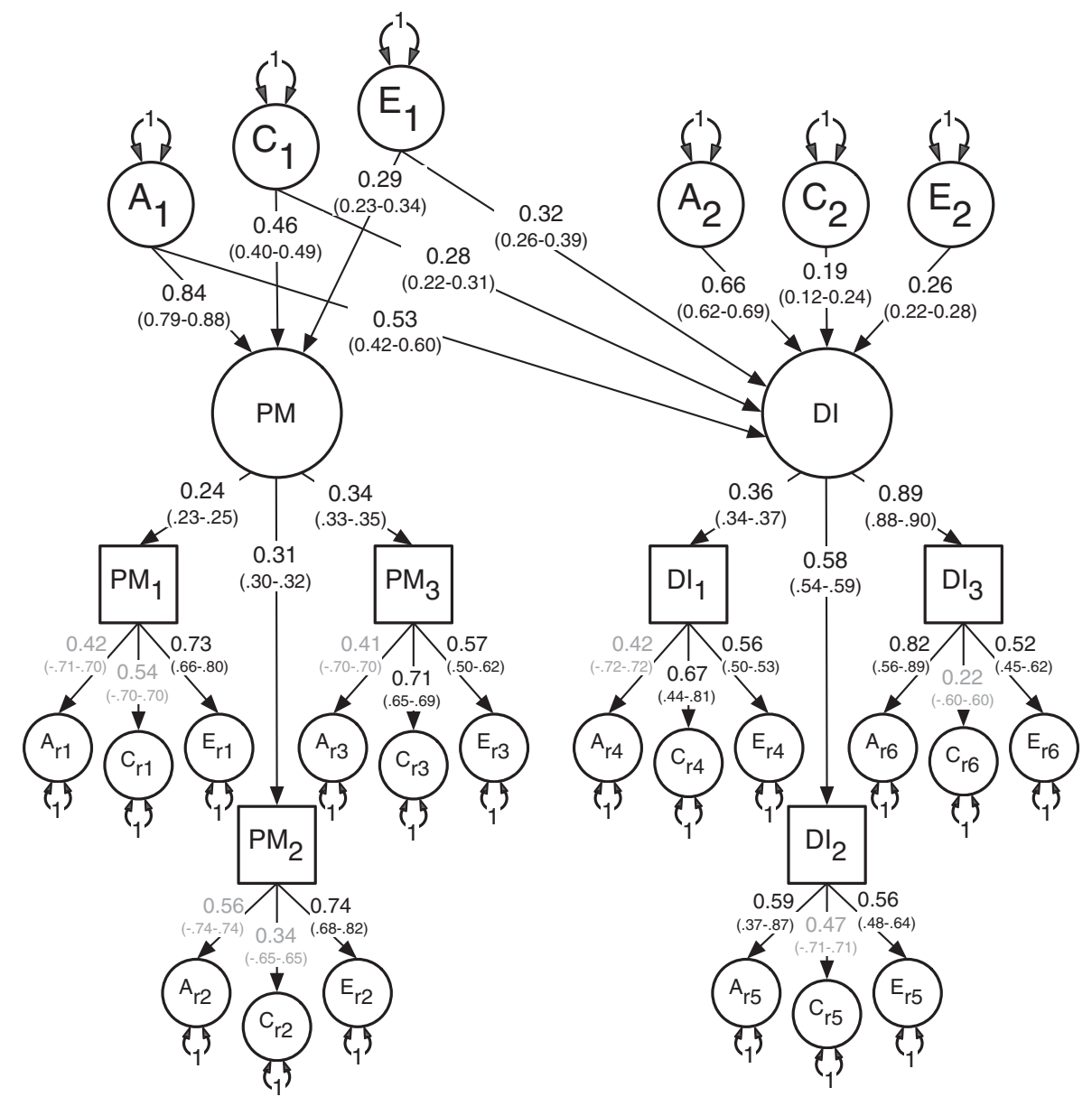

FIGURE 2

Best-fitting non-causal correlated liability model between the latent factors for Parental Monitoring (PM) and Drug Initiation (DI) with standardized path coefficients and $95 \%$ confidence intervals.

Note: $\mathrm{PM}_{1}=$ parent's knowledge of child's friends, $\mathrm{PM}_{2}=$ parent's knowledge of how child spent their money, $\mathrm{PM}_{3}=$ parent's knowledge of how child spent their free time, $\mathrm{DI}_{1}=$ cannabis initiation, $\mathrm{DI}_{2}=$ stimulant initiation, $\mathrm{DI}_{3}=$ cocaine initiation.

individual's environment is unlikely to be entirely random, but partly caused or correlated with his or her genotype (Scarr \& McCartney, 1983). Active CorGE describe cases whereby individuals 'select' or 'create' environments that are a function of their genotypes, whereas evocative CorGE describe cases whereby an individual's heritable behavior 'evokes' an environmental response (Neale \& Cardon, 1992). As an example of the latter, adoptees at high genetic risk for antisocial behavior have been found to be more likely to elicit more negative parenting from their adoptive parents (O'Connor et al., 1998). Both active and evocative CorGE are analogous to the unidirectional 'drug use causes PM' hypothesis that our data do not support. If parental knowledge derives primarily from voluntary disclosures rather than active parental surveillance (Stattin \& Kerr, 2000), then our results suggest that adolescents' tendency to avoid telling their parents about their activities and whereabouts when they are engaged in drug use, or other forms of delinquent behavior, may be a function of their genetic predisposition to drug use. Another form of CorGE arises because environments in which individuals develop are provided by their biological relatives and are known as instances of passive CorGE (Neale \& Cardon, 1992). For example, children who are genetically predisposed to drug use may also experience a pathogenic environment whereby the tendency of parents to not monitor their children may be attributable the genes also increasing the risk of DI. Therefore, a high genetic predisposition to DI is correlated with exposure to an adverse environment - for example, low PM - because both genes and environment originally derive from the parents (Neale \& Cardon, 1992). This is consistent with our best-fitting correlated liability results. Children who are genetically predisposed to DI may live in a drug tolerant home wherein the behavioral tendency of parents to be less attentive of their children's whereabouts are underpinned by the same genes. As an example of the latter, adoptees at high genetic risk for antisocial behavior have been found to be more likely to 
elicit more negative parenting from their adoptive parents (O’Connor et al., 1998).

\section{Limitations}

Our findings must be interpreted in the context of five potential limitations. First is the representativeness of our twin data drawn from Caucasian Virginian males. Nevertheless, our results are likely generalizable to the population at large. Although males have a higher prevalence of drug use (Kendler et al., 2002), previous analyses using the same data suggest that it is broadly representative of U.S. males and does not differ from the general population in rates of psychopathology, drug use, and abuse (Kendler, Karkowski et al., 2000). Second, because the difference in fit between the reciprocal causation and the correlated liability model was marginal, the power to rule out this competing hypothesis may be insufficient. Third, our modeling was not exhaustive, and since the confidence intervals on the item-specific shared environmental factors spanned zero, these parameters were dropped in order to identify a model that simultaneously fitted both the correlated liability and the reciprocal parameters to the data. This hybrid model provided a very poor fit to the data when compared to the correlated liability model $(\Delta-2 \mathrm{LL}=-1.93, \Delta d f=2, p<.001)$. Fourth, because we relied on self-reports of PM, it is unclear if drug use was associated with actual versus perceived changes in PM. Finally, demands on computational efficiency imposed by raw ordinal data analyses meant that our analyses were necessarily restricted to three PM and three DI items. We analyzed 10 additional three-item combinations from the $11 \mathrm{PM}$ as well as three-item combinations of the illicit substance initiation items. In all cases, we found irrespective of which combination of PM and DI items were used, that the non-causal, correlated liability model provided the best fit to the data.

\section{Acknowledgments}

Funding was received from the US National Institute on Drug Abuse (R00DA023549 \& DA-018673). This work was also supported by NIH grants AA07535 and AA07728. We also thank the twins for their cooperation.

\section{Conflict of Interest}

None.

\section{References}

Belli, R. F. (1998). The structure of autobiographical memory and the event history calendar: Potential improvements in the quality of retrospective reports in surveys. Memory, 6, 383-406.

Boker, S. M., Neale, M. C., Maes, H. H., Wilde, M. J., Spiegel, M., Brick, T. R., ... Fox, J. (2015). Multipurpose software for statistical modeling. Retrieved from http://openmx.psyc. virginia.edu.
Boyle, M. H., Offord, D. R., Racine, Y. A., Szatmari, P., Fleming, J. E., \& Links, P. S. (1992). Predicting substance use in late adolescence - results from the ontario child health study follow-up. American Journal of Psychiatry, 149, 761-767.

Caspi, A., Moffitt, T. E., Newman, D. L., \& Silva, P. A. (1996). Behavioral observations at age 3 years predict adult psychiatric disorders. Longitudinal evidence from a birth cohort. Archives of General Psychiatry, 53, 1033-1039.

Casswell, S., Pledger, M., \& Pratap, S. (2002). Trajectories of drinking from 18 to 26 years: Identification and prediction. Addiction, 97, 1427-1437.

Celdran, E., Bekett, P. R., \& Roberts, D. J. (1976). An experimental and clinical pharmacological study of the influence of triamterene on the diuretic and saluretic properties of furosemide xantinol. Arzneimittel-Forschung, 26, 20732076.

Chassin, L., Pillow, D. R., Curran, P. J., Molina, B. S., \& Barrera, M. J. (1993). Relation of parental alcoholism to early adolescent substance use: A test of three mediating mechanisms. Journal of Abnormal Psychology, 102, 3-19.

Chassin, L., Pitts, S. C., \& Prost, J. (2002). Binge drinking trajectories from adolescence to emerging adulthood in a high-risk sample: Predictors and substance abuse outcomes. Journal of Consulting and Clinical Psychology, 70, 67-78.

Colder, C. R., Campbell, R. T., Ruel, E., Richardson, J. L., \& Flay, B. R. (2002). A finite mixture model of growth trajectories of adolescent alcohol use: Predictors and consequences. Journal of Consulting and Clinical Psychology, 70, 976-985.

Dick, D. M., Latendresse, S. J., Lansford, J. E., Budde, J. P., Goate, A., Dodge, K. A., ... Bates, J. E. (2009). Role of GABRA2 in trajectories of externalizing behavior across development and evidence of moderation by parental monitoring. Archives of General Psychiatry, 66, 649657.

Dick, D. M., Meyers, J. L., Latendresse, S. J., Creemers, H. E., Lansford, J. E., Pettit, G. S., ... Huizink, A. C. (2011). CHRM2, parental monitoring, and adolescent externalizing behavior: Evidence for gene-environment interaction. Psychological Science, 22, 481-489.

Dick, D. M., Viken, R., Purcell, S., Kaprio, J., Pulkkinen, L., \& Rose, R. J. (2007). Parental monitoring moderates the importance of genetic and environmental influences on adolescent smoking. Journal of Abnormal Psychology, 116, 213218.

Dishion, T. J., \& Loeber, R. (1985). Adolescent marijuana and alcohol use - The role of parents and peers revisited. American Journal of Drug and Alcohol Abuse, 11, $11-25$.

Dubow, E. F., Boxer, P., \& Huesmann, L. R. (2008). Childhood and adolescent predictors of early and middle adulthood alcohol use and problem drinking: The Columbia county longitudinal study. Addiction, 103, 36-47.

Duffy, D. L., \& Martin, N. G. (1994). Inferring the direction of causation in cross-sectional twin data: Theoretical and empirical considerations. Genetic Epidemiology, 11, 483-502. 
Ellickson, P. L., Martino, S. C., \& Collins, R. L. (2004). Marijuana use from adolescence to young adulthood: Multiple developmental trajectories and their associated outcomes. Health Psychology, 23, 299-307.

Englund, M. M., Egeland, B., Oliva, E. M., \& Collins, W. A. (2008). Childhood and adolescent predictors of heavy drinking and alcohol use disorders in early adulthood: A longitudinal developmental analysis. Addiction, 103, 23-35.

Fergusson, D. M., \& Lynskey, M. T. (1998). Conduct problems in childhood and psychosocial outcomes in young adulthood: A prospective study. Journal of Emotional and Behavioral Disorders, 6, 2-18.

Freedman, D., Thornton, A., Camburn, D., Alwin, D., \& Young-Demarco, L. (1988). The life history calendar: A technique for collecting retrospective data. Sociological Methodology, 18, 37-68.

Freisthler, B., Gruenewald, P. J., Johnson, F. W., Treno, A. J., \& Lascala, E. A. (2005). An exploratory study examining the spatial dynamics of illicit drug availability and rates of drug use. Journal of Drug Education, 35, 15-27.

Freisthler, B., Needell, B., \& Gruenewald, P. J. (2005). Is the physical availability of alcohol and illicit drugs related to neighborhood rates of child maltreatment? Child Abuse and Neglect, 29, 1049-1060.

Gfroerer, J. (1987). Correlation between drug use by teenagers and drug use by older family members. American Journal of Drug and Alcohol Abuse, 13, 95-108.

Gillespie, N. A., Gehrman, P., Byrne, E. M., Kendler, K. S., Heath, A. C., \& Martin, N. G. (2012). Modeling the direction of causation between cross-sectional measures of disrupted sleep, anxiety and depression in a sample of male and female Australian twins. Journal of Sleep Research, 21, 675-683.

Gillespie, N. A., Lichtman, A. H., \& Kendler, K. S. (2013). The genetics of cannabis use and cannabis use disorders. In P. Miller (Ed.), Biological research on addiction, comprehensive addictive behaviors and disorders. Vol. 2 (pp. 523-529). Amsterdam: Elsevier.

Gillespie, N. A., Lubke, G. H., Gardner, C. O., Neale, M. C., \& Kendler, K. S. (2012). Two-part random effects growth modeling to identify risks associated with alcohol and cannabis initiation, initial average use and changes in drug consumption in a sample of adult, male twins. Drug and $\mathrm{Al}$ cohol Dependence, 123, 220-228.

Gillespie, N. A., Neale, M. C., \& Kendler, K. S. (2009). Pathways to cannabis abuse: A multi-stage model from cannabis availability, cannabis initiation and progression to abuse. Addiction, 104, 430-438.

Gillespie, N. A., Zhu, G., Neale, M. C., Heath, A. C., \& Martin, N. G. (2003). Direction of causation modeling between cross-sectional measures of parenting and psychological distress in female twins. Behavior Genetics, 33, 383-396.

Glaser, C. B., Karic, L., \& Cohen, A. B. (1977). Low pH stability of alpha-1-antititrypsin. Biochimica et Biophysica Acta, 491, $325-330$.

Heath, A. C., Kessler, R. C., Neale, M. C., Hewitt, J. K., Eaves, L. J., \& Kendler, K.S. (1993). Testing hypotheses about direction of causation using cross-sectional family data. $B e$ havior Genetics, 23, 29-50.

Helzer, J. E., Bucholz, K. K., \& Robins, L. N. (1992). Results of the epidemiologic catchment area survey. In J. E. Helzer \& G. J. Canino (Eds.), Alcoholism in North America, Europe and Asia. (pp. 79-95). New York: Oxford University Press.

Ingram, M. (1976). The tom gibson memorial lecture. The microbiological role of nitrite in meat products. Society for Applied Bacteriology Symposium Series, 4, 1-18.

Jackson, K. M., \& Sher, K. J. (2006). Comparison of longitudinal phenotypes based on number and timing of assessments: A systematic comparison of trajectory approaches II. Psychology of Addictive Behaviors, 20, 373-384.

Jones, M. M., Ogilvie, J. W., \& Ackers, G. K. (1976). Active enzyme gel chromatography. I. Experimental aspects. Biophysical Chemistry, 5, 339-350.

Kendler, K. S. (1996). Parenting: A genetic-epidemiologic perspective. American Journal of Psychiatry, 153, 11-20.

Kendler, K. S., Bulik, C. M., Silberg, J., Hettema, J. M., Myers, J., \& Prescott, C. A. (2000). Childhood sexual abuse and adult psychiatric and substance use disorders in women An epidemiological and cotwin control analysis. Archives of General Psychiatry, 57, 953-959.

Kendler, K. S., Chen, X., Dick, D., Maes, H., Gillespie, N., Neale, M. C., \& Riley, B. (2012). Recent advances in the genetic epidemiology and molecular genetics of substance use disorders. Nature Neuroscience, 15, 181-189.

Kendler, K. S., \& Gardner, C. O. (2010). Dependent stressful life events and prior depressive episodes in the prediction of major depression: The problem of causal inference in psychiatric epidemiology. Archives of General Psychiatry, 67, 1120-1127.

Kendler, K. S., Karkowski, L. M., Neale, M. C., \& Prescott, C. A. (2000). Illicit psychoactive substance use, heavy use, abuse, and dependence in a US population-based sample of male twins. Archives of General Psychiatry, 57, 261-269.

Kendler, K. S., \& Myers, J. (2009). A developmental twin study of church attendance and alcohol and nicotine consumption: A model for analyzing the changing impact of genes and environment. American Journal of Psychiatry, 166, 1150-1155.

Kendler, K. S., Neale, M. C., Thornton, L. M., Aggen, S. H., Gilman, S. E., \& Kessler, R. C. (2002). Cannabis use in the last year in a US national sample of twin and sibling pairs. Psychological Medicine, 32, 551-554.

Kendler, K. S., \& Prescott, C. A. (2006). Genes, environment, and psychopathology: Understanding the causes of psychiatric and substance use disorders (1st ed.). New York: The Guilford Press.

Kendler, K. S., Sham, P. C., \& MacLean, C. J. (1997). The determinants of parenting: An epidemiological, multi-informant, retrospective study. Psychological Medicine, 27, 549-563.

Latendresse, S. J., Rose, R. J., Viken, R. J., Pulkkinen, L., Kaprio, J., \& Dick, D. M. (2008). Parenting mechanisms in links between parents' and adolescents' alcohol use 
behaviors. Alcoholism: Clinical and Experimental Research, 32, 322-330.

Latendresse, S. J., Rose, R. J., Viken, R. J., Pulkkinen, L., Kaprio, J., \& Dick, D. M. (2009). Parental socialization and adolescents' alcohol use behaviors: Predictive disparities in parents' versus adolescents' perceptions of the parenting environment. Journal of Clinical Child \& Adolescent Psychology, 38, 232-244.

Li, F. Z., Duncan, T. E., \& Hops, H. (2001). Examining developmental trajectories in adolescent alcohol use using piecewise growth mixture modeling analysis. Journal of Studies on Alcohol, 62, 199-210.

Lynskey, M. T., \& Fergusson, D. M. (1995). Childhood conduct problems, attention-deficit behaviors, and adolescent alcohol, tobacco, and illicit drug use. Journal of Abnormal Child Psychology, 23, 281-302.

Maggs, J. L., Patrick, M. E., \& Feinstein, L. (2008). Childhood and adolescent predictors of alcohol use and problems in adolescence and adulthood in the National Child Development Study. Addiction, 103, 7-22.

Manzardo, A. M., Penick, E. C., Knop, J., Nickel, E. J., Hall, S., Jensen, P., ... Gabrielli, W. F. (2005). Developmental differences in childhood motor coordination predict adult alcohol dependence: Proposed role for the cerebellum in alcoholism. Alcoholism: Clinical and Experimental Research, 29, 353-357.

McDermott, D. (1984). The relationship of parental drug use and parents attitude concerning adolescent drug use to adolescent drug use. Adolescence, 19, 89-97.

McGue, M., Slutske, W., \& Iacono, W. G. (1999). Personality and substance use disorders: II. Alcoholism versus drug use disorders. Journal of Consulting and Clinical Psychology, 67, 394-404.

Neale, M. C. (1999). Mx: Statistical modelling (5th ed.). Richmond, VA: Department of Psychiatry, Virginia Commonwealth University.

Neale, M. C., \& Cardon, L. R. (1992). Methodology for genetic studies of twins and families (1st ed.). Dordrecht: Kluwer Academic Publishers.

Neale, M. C., Duffy, D. L., \& Martin, N. G. (1994). Direction of causation - Reply to commentaries. Genetic Epidemiology, 11, 463-472.

Neale, M. C., Walters, E., Health, A. C., Kessler, R. C., Perusse, D., Eaves, L. J., \& Kendler, K. S. (1994). Depression and parental bonding: Cause, consequence, or genetic covariance? Genetic Epidemiology, 11, 503-522.
O’Connor, T. G., Deater-Deckard, K., Fulker, D., Rutter, M., \& Plomin, R. (1998). Genotype-environment correlations in late childhood and early adolescence: Antisocial behavioral problems and coercive parenting. Developmental Psychology, 34, 970-981.

Parker, G., Tupling, H., \& Brown, L. B. (1979). A parental bonding instrument. British Journal of Medical Psychology, $52,1-10$.

Pickles, A., Neale, M., Simonoff, E., Rutter, M., Hewitt, J., Meyer, J., ... Eaves, L. (1994). A simple method for censored age-of-onset data subject to recall bias: Mothers' reports of age of puberty in male twins. Behavior Genetics, 24, 457468.

Pitkanen, T., Kokko, K., Lyyra, A. L., \& Pulkkinen, L. (2008). A developmental approach to alcohol drinking behaviour in adulthood: A follow-up study from age 8 to age 42 . Addiction, 103, 48-68.

Scarr, S., \& McCartney, K. (1983). How people make their own environments: A theory of genotype greater than environment effects. Child Development, 54, 424-435.

Stattin, H., \& Kerr, M. (2000). Parental monitoring: a reinterpretation. Child Development, 71, 1072-1085.

Szobot, C. M., \& Bukstein, O. (2008). Attention deficit hyperactivity disorder and substance use disorders. Child and Adolescent Psychiatric Clinics of North America, 17, 309323.

Verweij, K. J., Zietsch, B. P., Lynskey, M. T., Medland, S. E., Neale, M. C., Martin, N. G., ... Vink, J. M. (2010). Genetic and environmental influences on cannabis use initiation and problematic use: A meta-analysis of twin studies. Addiction, 105, 417-430.

Wiesner, M., Weichold, K., \& Silbereisen, R. K. (2007). Trajectories of alcohol use among adolescent boys and girls: Identification, validation, and sociodemographic characteristics. Psychology of Addictive Behaviors, 21, 62-75.

Windle, M., Mun, E. Y., \& Windle, R. C. (2005). Adolescentto-young adulthood heavy drinking trajectories and their prospective predictors. Journal of Studies on Alcohol, 66, 313-322.

Young, S. E., Mikulich, S. K., Goodwin, M. B., Hardy, J., Martin, C. L., Zoccolillo, M. S., \& Crowley, T. J. (1995). Treated delinquent boys substance use - Onset, pattern, relationship to conduct and mood disorders. Drug and Alcohol Dependence, 37, 149-162. 